\title{
From Indifference to Delight: Gauging Users' Preferences Using the Kano Model
}

\author{
Gabriela Castro Gessner \\ Cornell University, USA
}

\author{
Zoe Chao \\ Penn State University, USA
}

\section{Introduction}

The library user's perspective and experience are an essential component in the design of services and spaces in libraries. User involvement and feedback during the planning and development process ensures that our spaces, websites, and services meet user expectations through the best and most suitable solutions. As a result of this emphasis, there has been an increase in the number of studies and projects under the user experience umbrella that detail qualitative research assessment methods utilized in libraries. Prominent in recent library literature are those that are broad in scope, such as those aiming to detail the various aspects or steps undertaken by patrons (students or faculty) in their research process. ${ }^{1}$ There are also many examples that describe and illustrate methods utilized to answer very specific research questions, such as usability testing for websites ${ }^{2}$ or those utilized to reconfigure library services or library spaces. ${ }^{3}$

Many of these studies are inspired by ethnography and rely on qualitative research methods that involve interviews or focus groups and provide rich user information that is often unavailable via other means. The benefit of such methods is a more nuanced and holistic understanding of the experience, interactions, and perceptions that our users have about the library. One of the drawbacks, however, is that those research methods are usually time- and resource-intensive. While their benefit is not to be underestimated, alternative methods might serve well when there are time constraints and limited resources. It is in this context that we situate our paper.

We provide an overview of the Kano Model and its use in total quality management (an organizational activity with commitment to quality achieved through the employee in a continuous improvement process) ${ }^{4}$ to derive customers' satisfaction and needs, and some of its application in libraries. It is a versatile method as it can be used to elicit information in libraries regarding online or physical services and was used successfully to evaluate customer needs for Guadalajara's Digital Library. ${ }^{5}$ The drawback may be that it works best for very specific and targeted research questions and does not offer the depth that some interviews or other qualitative methods provide. One useful aspect is that it forces the researcher to carefully think about what is essential to find out from users and make those thoughts explicit and precise in the questions asked of users.

In this paper, we share two different applications of the Kano Model, one for space at Cornell University Library, and one for digital signage at Penn State University Library. Both projects generate insights on user perspectives and provide direction for next steps. We discuss the strengths and challenges of using the Kano Model and how we moved forward based on the obtained results.

\section{Kano Model}

The Kano Model is based on the work of an emeritus engineering professor, Noriaki Kano, in the department of management science at the University of Tokyo. The pivotal, coauthored article that details his ideas regarding quality and customer satisfaction was published in Japanese in $1984 .{ }^{6}$ In the intervening 34 years, there have been numerous references to these ideas and his work regarding total quality management. 
Since the 1984 publication, the Kano Model has been a popular quality model used in marketing because it helps identify specific attributes that have the potential to elicit customer delight and its opposite, dislike. Since the original method was proposed, modifications have extended or attempted to extend its quantitative power in support of measuring the relationship between customer satisfaction and customer needs or requirements. ${ }^{7}$ Examples of uses of the Kano Model include its application for new designs in Turkish jewelry and tile-making ${ }^{8}$ and supplier development in manufacturing chains, ${ }^{9}$ among others.

\section{Premise of Kano Model}

Violante and Vezzetti provide a detailed overview and history of the Kano Model and its variants. They state that "[s]ince the attributes of a product/service do not play the same role in satisfying the customers' needs, identifying the critical factors that determine satisfaction is essential to the sustained success of any organization." ${ }^{10}$ In other words, not all service features or attributes are equally important to customers, and identifying the ones that increase satisfaction are critical for success. By way of example, let us take cars. One of the minimum requirements for a car is to have seats so it can be driven, but the fact that seats can be heated and adjusted to the height of the driver and/or passenger provides additional value above and beyond the minimum requirement of having seats. What is key in this example is the concept that the different qualities of the products or services we offer (heated and adjustable seats, for example) have an impact in eliciting customer satisfaction or dissatisfaction. Allocating resources and thought to increasing customer satisfaction by determining the qualities that matter to our users will be worth the effort.

\section{How the Kano Model Works}

There are three main steps in the Kano Model: a questionnaire, a scoring table, and an evaluation table. ${ }^{11}$ To these three steps, we add one more, which is the final tabulation of frequencies into a table that indicates which features or attributes are important to users or customers who participated in the study (figure 1 and table 1).

Step 1. The questionnaire, unlike survey or interview questions, is designed to include pairs of questions per product or service attribute. In other words, each question is about a single feature and is asked twice, once phrased from what the authors call a "functional" form and the second time from a "dysfunctional" form. The first question is to elicit how the person feels about having that feature or requirement present, and the second one asks how they feel if it is absent. Participants are asked to respond by only using short phrases that include the following words or express the same sentiment: like (or delight), expect (or must-have), neutral, tolerate (I can live with this) and dislike. According to Jan Moorman of UX Magazine, ${ }^{12}$ Kano posited that there are five different emotional responses to any given product feature, ranging from dislike to delight. Furthermore, the key to customer satisfaction was in finding the right combination to provide both surprise and delight.

Step 2: In the second step of the process, the responses from participants for each question, get noted in the scoring table. These tallies feed the third step in the process, which consists of identifying where the responses fit in the evaluation table. 
Fig.1. Kano Model three-step sequence: 1 questionnaire; 2 scoring table; 3 evaluation table (after Center for Quality Management Journal ${ }^{13}$ and Michael Schofield ${ }^{14}$ ).

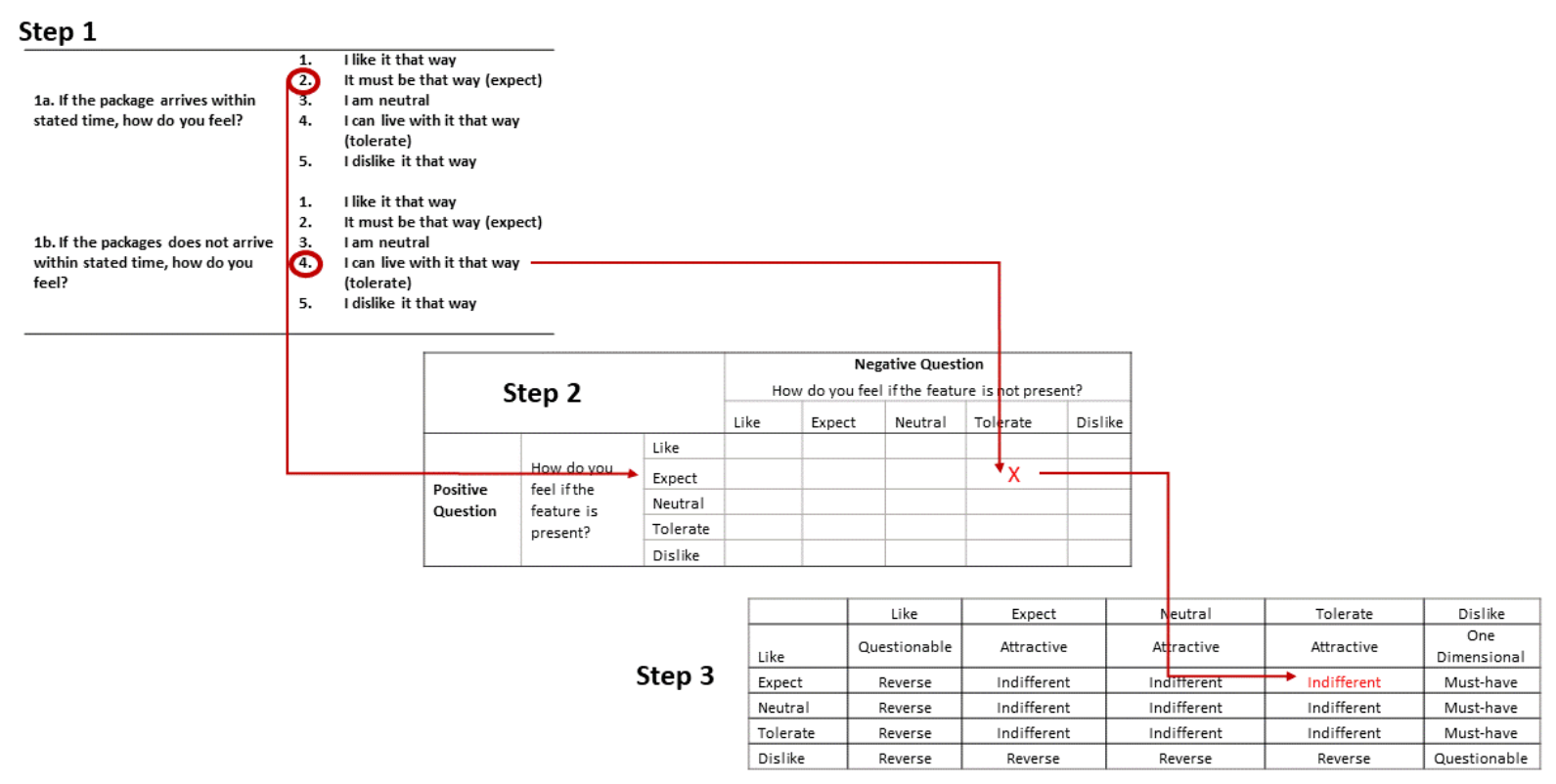

Step 3: The evaluation table is unique in that it is more like a matrix with pre-assigned values that correspond to the five types of responses elicited from participants (dislike to delight). This table classifies the quality attributes into six categories: Attractive, Must-be, One-Dimensional, Indifference, Reverse, and Questionable (see below). These categories are often represented in the literature in a graphical form to explain the relationships between customer satisfaction/dissatisfaction and functional/dysfunctional requirements in products (figure 2). The six categories are described as follows:

1. Attractive: Attributes which have the greatest influence in how satisfied the customer will be-the unexpected qualities in a product (e.g., in the early years of mobile phones, connecting to the internet).

2. Must-be: Attributes that are expected, often taken for granted. If they are unavailable, the customer will be very dissatisfied (e.g., having no brakes in a car).

3. One-Dimensional: Attributes that inform a linear relationship between the function of a product and customer satisfaction (e.g., better gas mileage provides more customer satisfaction, lower gas mileage greater dissatisfaction).

4. Indifference: Attributes whose presence or absence does not affect customers' satisfaction or dissatisfaction.

5. Reverse: Attributes whose presence causes dissatisfaction and whose absence results in customer satisfaction.

6. Questionable: A contradiction in client's response or a poorly phrased/understood question. 
Fig.2. Kano Model (after Violante and Vezzetti ${ }^{15}$ and Center for Quality Management Journal ${ }^{16}$ )

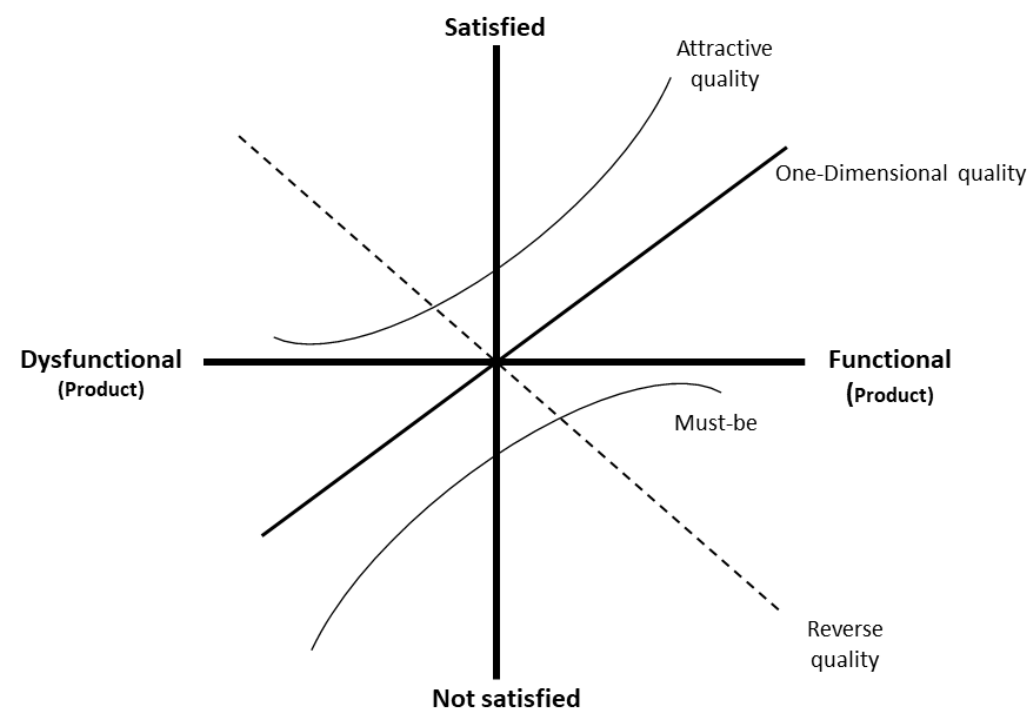

Step 4. In the final steps of analysis, after all results for each question have been collected, a new table that tabulates customer preferences per feature (question asked) is created. In table 1 below, the totals per column indicate participants' responses to each feature. Attribute number 3 garnered high "attractive" marks from participants, indicating to the researchers that that feature would be a very welcome addition to a product or service, while feature number 2 is something customers would expect for ongoing satisfaction with that product or service. When results are even on several dimensions, context may help clarify, and if not, further investigation regarding questions or study is needed.

Table 1. Tabulated results for each attribute from evaluation table (Step 4).

\begin{tabular}{|l|l|l|l|l|l|l|l|l|}
\hline $\begin{array}{l}\text { Attributes } \\
\text { Features }\end{array}$ & Attractive & Must-be & $\begin{array}{l}\text { One- } \\
\text { Dimensional }\end{array}$ & Indifference & Reverse & Questionable & Total & Grade \\
\hline No. 1 & 1 & 2 & 21 & & & & 24 & O \\
\hline No. 2 & 2 & 20 & & 1 & & 1 & 24 & M \\
\hline No. 3 & 14 & 1 & 6 & 1 & 2 & & 24 & A \\
\hline ...etc. & 6 & & 2 & 14 & 1 & 1 & 24 & I \\
\hline
\end{tabular}

\section{Kano Model Applied to Space Design-Cornell University Library}

\section{Background and research prompt}

Prior research studies and surveys conducted in the social sciences/humanities library (Olin Library) on the Cornell University campus had indicated that library carrel holders (all graduate students) frequently complained about the use of their assigned carrels by other students, namely undergraduates. They described how their books were rearranged, food detritus left behind, and, worst of all, the uneasiness they felt in asking carrel trespassers to move to another space. Carrels in this library are not open, closable spaces, but rather desks with a set of shelves above them that also function as privacy dividers. The carrel desks are located along the perimeter walls of the building, arranged in a single file one after the other and adjacent to book stacks. Non-carrel holders who use the library feel that if carrels are vacant, they are open for their own use, despite signage and policies that indicate they are reserved for specific individuals (graduate students). 
Ongoing complaints voiced by graduate students who were assigned carrels prompted the access services librarian in Olin Library to find a solution that would help them. She considered creating a graduate-studentonly shared space in another location in the same library. Conceptually, the space was envisioned not to duplicate the features of another existing graduate student library lounge with many other amenities, but rather provide a small subset of graduate students a place to study devoid of undergraduate intrusion. As such, it would only be available to about 30-35 designated graduate students and only provide basic functionality with desks, chairs (and outlets), and a shelf or location to check out and store library materials for each person assigned to the room. Access to the room would be restricted either by ID card or keypad controls. Carrel holders signing up to use the shared graduate student room would relinquish the use of an assigned open carrel elsewhere in Olin Library.

\section{Method}

To explore if the idea of a shared graduate student space was of interest to current graduate students who are carrel holders, we developed a set of questions to highlight the main features of the proposed new space. We interviewed 16 graduate students (all open carrel holders), using the Kano Model as a means to tease out their potential satisfaction and perception of value in the idea of a shared graduate student space. Interviews were scheduled in the library and were conducted by two library staff members.

Participants were read a description of the anticipated shared room/space and the features it would have. They were then asked to answer six pairs of questions using the Kano Model phrasing, as in this example:

1a. How would you feel about the availability of an assigned study space in Olin that would be shared with other graduate students?

1b. How would you feel if this assigned shared space for graduate students were not available?

The six questions specified particular features available or connected with using the new space. All students were asked to answer using the stipulated phrasing (I like it, I expect it, I am neutral, I can tolerate it (or I can live with that), and I dislike it). Their responses were tallied according to the scoring table illustrated above in steps 1 and 2. The table below (table 2) captures the attributes we asked about (in positive and negative form) and the responses each garnered after all interviews were completed.

Table 2. Example of attributes asked about new space in Olin Library and their evaluation results

\begin{tabular}{|l|l|l|}
\hline & Questions/ Features regarding Space & $\begin{array}{l}\text { Evaluation Category } \\
\text { (derived from totals from all 16 } \\
\text { participants) }\end{array}$ \\
\hline Feature 1 & $\begin{array}{l}\text { Availability of an assigned study space in Olin } \\
\text { that is shared }\end{array}$ & Attractive \\
\hline Feature 2 & Restricted access by card or keypad & Indifferent \& One-Dimensional \\
\hline Feature 3 & $\begin{array}{l}\text { Sharing space with as many as 30 other } \\
\text { graduate students }\end{array}$ & Indifferent \\
\hline Feature 4 & Desk/chair not assigned to individual & Reverse \\
\hline Feature 5 & $\begin{array}{l}\text { Option to check out and safely store library } \\
\text { and other personal materials }\end{array}$ & Attractive \\
\hline Feature 6 & $\begin{array}{l}\text { Relinquish of current carrel if assigned to } \\
\text { new shared space }\end{array}$ & Reverse \\
\hline
\end{tabular}

\section{Analysis and Results}

After all responses were tabulated using the evaluation table, we learned that students would be delighted to both have a graduate student space that is shared with other graduate students (feature 1) and have the 
opportunity to check library materials out and safely keep them in that space (feature 5). If they shared such a graduate space with others, they would prefer that desks or seats within that room be assigned (feature 4). More students felt indifferent to the idea of sharing a room with as many as 30 other graduate students (feature 3); in other words, this feature did not provide either satisfaction or dissatisfaction to them. However, almost an equal number would find that possibility attractive. Some students find themselves indifferent to restricting access to the shared space (feature 2), but an equal number of students felt that if the library provides this feature, the more satisfied they will be. Despite the positive response to the idea of a shared room, graduate students interviewed did not like the idea of relinquishing their open carrel to be able to use the room (feature 6). This was a key point. This information suggested that investing in a graduatestudent-assigned shared room would only work for graduate students if they were allowed to keep their carrels.

These results clearly pointed out that a new space would not be a welcome addition if it meant that they had to give up their private and individually assigned carrel in the library. The library saved itself a renovation by investigating in a very specific way what it would mean for the users of that space.

\section{Kano Model Applied to Digital Signage-Penn State Background}

In the summer of 2017, the Digital Signage Project Team at Penn State University Libraries (PSUL) was charged to develop the design of the newly acquired digital signs to be displayed by the main entrances at the Pattee-Paterno Library. Unlike the previous TV-like models, the new monitors included interactive touchscreens similar to a tablet and could be pivoted from horizontal orientation to vertical. Previous monitors could only display either promotions for library events and exhibitions or information about computer availability. The new vertical signs were set to function like a bulletin board displaying a combination of different information, including library events, available computers, and the open hours for the library building and café. Additional features such as the weather and time were positioned on the top right corner (see figure 3). The display itself was basically a single HTML page. The touchscreen interactive feature was not activated because there were no links available on the page. The UX Librarian was asked to evaluate if the setup of the new digital signs met users' needs. 
Fig. 3. The new digital sign at Pattee-Paterno Library, Penn State University, used for testing.

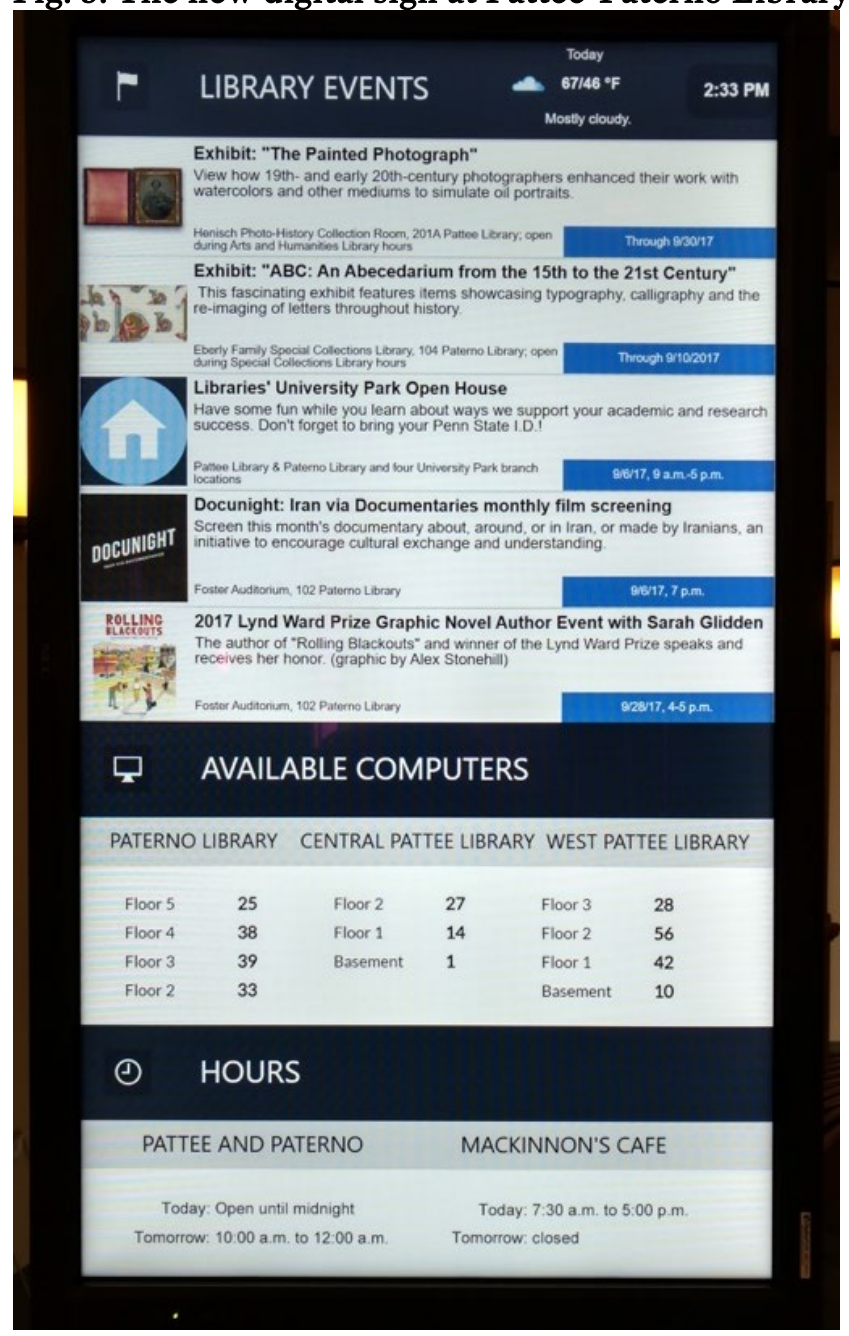

Considering the fixed, limited space of the interface and the rapid, immense traffic flow by these entrances, students' attention to or interaction with the signs are expected to be fairly brief in general. The design of these signs needed to be strategic in its use of content. The Kano Model's classification of product features was used to clarify which types of information students deemed to be essential and which to be trivial.

To decide what features to test, in addition to what was being displayed, a preliminary survey was conducted with library staff from the "Welcome Desk" to identify questions frequently asked by students. A total of 29 "Welcome Desk" staff participated in the preliminary survey. With their feedback, we identified that the most frequently asked question was, "Where is the restroom?" followed by, "Where is room xxx?" Other inquiries included locations of available computers/printers, group study rooms, hours for library spaces and café, and item locations for a specific subject (e.g., books about engineering). It was clear that wayfinding was the main concern for students and the floor plans with layouts of the rooms might be needed to address this information need. It would be a challenge to develop an effective interface to direct students to a specific room on the limited space of a digital sign. An additional factor is that the project team made a decision early on to break this project into manageable phases to keep development time and delivery time to reasonable lengths. Developing detailed floor plans at that point was deemed out of the project scope.

It was decided to use the current interface as the baseline to test the current content (i.e., time, weather, exhibitions and events, available computers, and hours) using the Kano Model questionnaire. In addition, the project team wanted to know if users would prefer a more image-based design and if the advantage of the 
touchscreen and addition of links to the interface would allow users to navigate more easily. To answer these questions, two more features were added to the questionnaire: interactive interface and big appealing images.

The survey and brief interviews were conducted adjacent to the library entrance and next to a new digital sign. Participants were introduced to the sign and the purpose of the study. They were then asked, "How do you feel when you see that the digital sign has the following information?" while showing them a list of features and the five response options: I like it, I expect it, It doesn't affect me, I can live with it, and I don't like it. After finishing the functional question for all the features, we asked them the dysfunctional or negative question, "How would you feel if the digital sign didn't have the following information?" with the same list of features and response options.

\section{Result and Analysis}

Twelve students participated in the digital sign feature survey. The results clearly indicated that the "available computers" information is a one-dimensional feature. All 12 participants responded they like it when "available computers" is present and they would by annoyed if they did not see the feature that indicates computer availability. Table 3 shows the tabulated results for all the features.

Table 3. Students' responses to the features of digital signs at the Pattee-Paterno Library.

\begin{tabular}{|l|l|l|l|l|l|l|}
\hline & Attractive & Must-be & $\begin{array}{l}\text { One- } \\
\text { dimensional }\end{array}$ & Indifference & Reverse & Questionable \\
\hline Available computers & & & 12 & & \\
\hline Library hours & 2 & & 6 & 4 & \\
\hline Library events & 2 & & 6 & 4 & \\
\hline Time & 4 & 2 & 6 & & \\
\hline Weather & 7 & & 5 & 3 & \\
\hline Interactive interface & 4 & 1 & 1 & 3 & 4 & 1 \\
\hline Big images & 4 & & & 3 & & \\
\hline
\end{tabular}

The responses did not generate a significantly preferred category, except for the "available computers." Both "library hours" and "library events" are categorized as one-dimensional by half of the responses, though onethird of the participants felt indifferent toward the features. The distinction between "attractive" and "indifferent" is less clear-cut than expected. For several features, there seems to be a split between these two categories. Interestingly, about one-third of the participants deemed "interactive interface" and "big images" as reverse features, meaning that the participants would rather not see the feature on the digital sign. For "interactive interface," students expressed concern over a scenario that they might not have time to wait for their turn if the screen was occupied by others. Likewise, they preferred not to see big images fearing that the images might hinder access to the needed information.

According to Daniel Zacarias, features are categorized by the most frequent responses and should be prioritized as followed: must-be features, one-dimensional, then attractive. ${ }^{17}$ As a result, the project team would invest their efforts in providing information for available computers, library hours, and library events, three one-dimensional features. Time and weather are considered as bonus features as participants pointed out that they have cellphones for time and weather information. Further study will be needed to test for both "interactive interface" and "big images" due to the close three-way split between attractive, indifferent, and reverse in the results. Hopefully, such ambiguity will be resolved by increasing the pool of participants. Although the study draws out rather complex responses from the participants, it provides an efficient and straightforward approach to help the project team prioritize next steps and focus on improving the essential elements. 


\section{Lessons Learned}

In both cases, the studies conducted were very specific and had a well-defined scope that fit the parameters of the Kano Model. Other kinds of qualitative methods would have also been appropriate, but perhaps taken more time to develop, conduct, and analyze. In the case of the graduate student space at Cornell, the interviews took longer to schedule than the actual time spent with students and analyzing. One lesson learned from the Cornell study is that we inadvertently inverted the positive and negative format of the questions for one feature, and that took some untangling in terms of figuring out the correct way to tabulate and interpret the results. The other thing we learned was that the format of asking questions-since we did this in person-sounded rather contrived to our interviewees. In order to maintain consistency with every participant, we repeated the questions exactly as we wrote them for every student and every feature, and we heard from our trial tests that we should explain the method in advance to them. That also helped them feel more comfortable providing responses using the stipulated words/short phrases we requested them to use (I like it, I tolerate it, etc.). Lastly, students generously clarified their selection or choice of answer after we concluded the interview, and that helped to fill some of the gaps or questions that their choice of response elicited. This would not have been achievable if we had not done this face-to-face.

Another possible confusion is that participants may misinterpret the five responses as continuous levels of intensity in sentiment, such as from strongly agree to strongly disagree. Because of the model's unique way of analyzing data, we should make it clear to participants that the survey is not an incremental 5-point Likert scale and the five expressions are discrete and should be taken at face value.

Asking participants how they feel about a non-existent feature can be a challenge. Participants may not be able to fully grasp the capabilities of the feature without experiencing it, as happened with the digital sign at Penn State. We originally speculated that users would be delighted by the touchscreen and the inclusion of appealing images, with the expectation that these two features would be "attractive" to them. It is possible, however, that students' responses and ensuing results are an indication of status quo bias ${ }^{18}$-the suggestion that any change from the current baseline (status quo) might be perceived as a loss. The participants anticipated that an interactive interface would be an obstacle for them to access information and could imagine a scenario where they had to wait for others to take their turn. They did not consider that a welldesigned interactive interface, including appealing images, could potentially bring them delight. On the other hand, it is logical not to expect too much from an absent feature because its development and future application might not occur. Though the Kano Model does not specify how many participants are needed, in the case of the digital signage study, more subjects would probably yield more meaningful results. Also, as time passes and technology evolves, users' viewpoints about a product might shift, and studies are always needed as expectations change.

\section{Conclusions}

The Kano structured model of question and answer scored on a table was an efficient and time-saving method for both library staff and library patrons. It forced us to isolate from the start the service aspects we wanted feedback on without resorting to more time-consuming research methods. Likewise, it provided quick answers and supporting evidence to facilitate decision-making for our administrators, allowing us to calibrate our services to match our users' needs.

In both cases, the path forward was very clear, even with the potential ambiguous results yielded at Penn State Library for one question. In essence, one of the most gratifying results of both projects was exactly the clear direction to follow. We found the application of this method by others to an online library environment encouraging ${ }^{19}$ and we hope this paper encourages others to make use of this tool.

-Copyright 2019 Gabriela Castro Gessner and Zoe Chao 


\section{Endnotes}

1. Gabriela Castro Gessner, Susette Newberry, Deborah Schmidle, and Kornelia Tancheva, "Humanists in the House of Learning: Academic Research Libraries' Role in Fostering Communities of Practice," in ACRL 2013 Proceedings (American Library Association, 2013), http://www.ala.org/acrl/sites/ala.org.acrl/files/content/conferences/confsandpreconfs/2013/papers/Ge ssner_etal_Humanists.pdf; Lynda M. Duke and Andrew D. Asher, College Libraries and Student Culture: What We Now Know (Chicago, American Library Association, 2011), 7, https://digitalcommons.iwu.edu/bookshelf/7; Nancy F. Foster and Susan Gibbons, eds., Studying Students: The Undergraduate Research Project at the University of Rochester (Chicago: Association of College and Research Libraries, 2007); Brenda Reeb and Susan Gibbons, "Students, Librarians, and Subject Guides: Improving a Poor Rate of Return," portal: Libraries and the Academy 4, no. 1 (2004): 123130, https://muse.jhu.edu/; Kornelia Tancheva, Gabriela Castro Gessner, Neely Tang, Erin Eldermire, Heather Furnas, Darcy Branchini, Gail Steinhart, and Nancy F. Foster, "A Day in the Life of a (Serious) Researcher: Envisioning the Future of the Research Library," Ithaka S+R, Last Modified 8 March 2016, https://doi.org/10.18665/sr.277259.

2. Jennifer Emanuel, "Usability of the VuFind Next-Generation Online Catalog," Information Technology and Libraries, 30 (2011): 44-52, https://doi.org/10.6017/ital.v30i1.3044; Helen Timpson and Gemma Sansom, "A Student Perspective on E-resource Discovery: Has the Google Factor Changed Publisher Platform Searching Forever?" Serials Librarian 61 (2011): 253-266, https://doi:10.1080/0361526X.2011.592115; J. C. Fagan, M. A. Mandernach, C.S. Nelson, J. R. Paulo, and G. Saunders, "Usability Test Results For A Discovery Tool in An Academic Library," Information Technology and Libraries 31 (2012), 83-112, https://doi.org/10.6017/ital.v31il.1855.

3. Susan Thompson, "Students Use of Library Computers: Are Desktop Computers Still Relevant in Today's Libraries?" Information Technology and Libraries. 31 (2012): 20-33, https://doi.org/10.6017/ital.v31i4.2284; Steve Borrelli, Zoe Chao and Chao Su, "Reflecting the Voice of the Student: A Case Study from the Pennsylvania State University Using Mixed-Methods in Assessing Space,” Library Management, 40 (2019): 121-127, https://doi.org/10.1108/LM-10-2017-0102.

4. Travis Jones and Kimberly K. Buch, “Total Quality Management," in The SAGE Encyclopedia of Industrial and Organizational Psychology, 2nd edition, edited by Steven G. Rogelberg (Thousand Oaks, CA: SAGE Publications, Inc, 2017), 1632-1635, http://dx.doi.org/10.4135/9781483386874.n559.

5. Cecilia Garibay, Humberto Gutiérrez, and Arturo Figueroa, "Evaluation of a Digital Library By Means of Quality Function Deployment (QFD) and the Kano Model," The Journal of Academic Librarianship 36 (2010): 125-132, https://doi.org/10.1016/j.acalib.2010.01.002.

6. Noriaki Kano, K. Seraku, F. Takahashi, and S. Tsuji, "Attractive Quality and Must-Be Quality Hinshitsu Quality,” The Journal of the Japanese Society for Quality Control 14 (1984): 39-48.

7. Maria Grazia Violante and Enrico Vezzetti, "Kano Qualitative vs Quantitative Approaches: An Assessment Framework for Products Attributes Analysis," Computers in Industry 86 (2017): 15-25, https://doi.org/10.1016/j.compind.2016.12.007.

8. Bilsen Bilgili, Aysel Erciş and Sevtap Ünal, "Kano Model Application in New Product Development and Customer Satisfaction (Adaptation of Traditional Art of Tile Making to Jewelries)," Procedia Social and Behavioral Sciences 24 (2011): 829-846, https://doi.org/10.1016/j.sbspro.2011.09.058.

9. C.V. Sunil Kumar and Srikanta Routroy, "Demystifying Manufacturer Satisfaction through Kano Model, Materials Today: Proceedings 2, no. 4-5 (2015): 1585-1594, https://doi.org/10.1016/j.matpr.2015.07.085.

10. Violante and Vezzetti, 15.

11. Violante and Vezzetti, 15.

12. Jan Moorman, "Leveraging the Kano Model for Optimal Results," UX Magazine 882, October 9, 2012, https://uxmag.com/articles/leveraging-the-kano-model-for-optimal-results.

13. David Walden, ed., "A Special Issue on Kano's Methods for Understanding Customer-Defined Quality," Center for Quality Management Journal, 2 (1993): 2-36, http://walden-family.com/public/cqm-journal/24-Whole-Issue.pdf.

14. Michael Schofield, "Applying the Kano Model to Improve UX," Computers in Libraries 36 (2016): 28-32.

15. Violante and Vezzetti.

16. Walden, "A Special Issue." 
17. Daniel Zacarias, "The Complete Guide to the Kano Model: Prioritizing Customer Satisfaction and Delight," Folding Burritos, https://foldingburritos.com/kano-model/.

18. William Samuelson and Richard Zeckhauser, "Status Quo Bias in Decision Making," Journal of Risk and Uncertainty 1 (1988): 7-59, https://doi-org.proxy.library.cornell.edu/10.1007/BF00055564.

19. Garibay, Gutierrez and Figueroa, "Evaluation of a Digital Library"; Schofield, "Applying the Kano Model." 